\section{Incoherencias sistemáticas en el examen del acusado en el proceso penal peruano y la necesidad de su compatbilidad con el sistema acusatorio}

\section{Systematic inconsistencies in the review of the accused in the criminal process in Perú and the need of it's support with adversarial system}

\section{INTRODUCCIÓN}

En un escenario como el peruano en el que, aún se encuentra sumamente arraigada la ideología inquisitiva en el inconsciente colectivo, consideramos que resulta un eje esencial para el análisis, a propósito de la necesidad de consolidar el principio acusatorio como una institución propia del Estado constitucional de Derecho, la forma en que debe concebirse y producirse la declaración del acusado en el nuevo proceso penal, sobre todo, teniendo en cuenta que, la referida ideología inquisitiva, es una herencia cultural de siglos de malas prácticas, que no será posible cambiar de la noche a la mañana, mucho menos, con la simple promulgación y vigencia del nuevo Código.

¿Cómo hacer entonces para que los abogados, jueces y fiscales, ingresen al "duelo de prácticas", premunidos de ideas claras que eviten el fracaso de la reforma?; ¿Son adecuadas y compatibles con el Principio acusatorio, las normas contempladas en el nuevo Código Procesal Penal sobre el examen del acusado?; ¿Cuáles deben ser los nuevos parámetros en la lógica del examen del acusado para que los fiscales y abogados realicen objeciones y los jueces resuelvan con predictibilidad al respecto?; ¿Qué problemas y tendencias se están presentando en los distritos judiciales en los que ya está vigente el nuevo Código Procesal Penal?; ¿̇Será necesario y conveniente proponer algún cambio legislativo?.

Como se puede advertir, la problemática planteada tiene que ver con el análisis de la instalación de la oralidad especialmente en el juzgamiento, por lo que el presente trabajo, de acuerdo a las sugerencias del Profesor Mauricio Duce, es básicamente de diagnóstico y descripción del problema con la identificación especifica de aspectos positivos y negativos, de nuestra realidad objetiva; sin embargo, a manera de recomendaciones con cargo a efectuar un trabajo más profundo, intentaremos esbozar algunas propuestas de solución que facilite el cambio cultural necesario en forma más o menos homogénea en el escenario nacional.

Estamos convencidos de que este es un tema esencial en el proceso de reforma porque en la actualidad, jueces, fiscales, abogados y ciudadanía en general, tanto en los distritos judiciales en los que aún no rige, como en aquéllos en los que ya se encuentra en vigencia el Nuevo Código Procesal Penal, no disponen de pautas claras ni mucho menos uniformes. Nuestro objetivo entonces, es detectar y puntualizar las deficiencias y sugerir parámetros claros y herramientas, para lograr el cambio cultural que la reforma demanda.

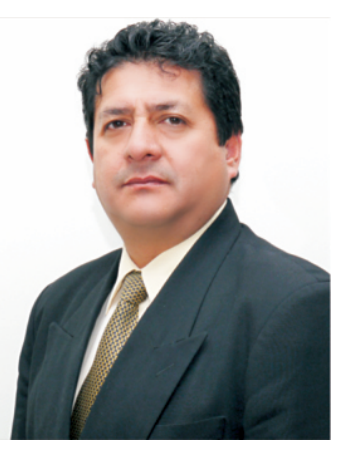

Iván Guerrero López

Poder Judicial, Corte Superior de Justicia de Junín

1 Mg. en Derecho con mención en ciencias Penales, Docente en la Academia de la Magistratura, Presidente de la Sala de Apelaciones del Nuevo sistema anticorrupción en Junín; miembro de la Comisión de Implementación del Código Procesal Penal en el Distrito Judicial de Junín 


\section{El examen de acusados en el Código de Procedimientos Penales de 1940}

Para una cabal comprensión del tema planteado y su contexto, resulta insoslayable referirnos a las características del modelo procesal que se intenta reformar, en el tema específico que abordamos. El viejo Código de 1940, en su versión original e incluso con una modificación del año 2004, establecía que, luego de la formulación de cargos, si no existía conformidad, el Fiscal procedía al examen del acusado y luego lo debería hacer el director de debates (Uno de los Jueces del Tribunal), y a continuación, los demás miembros de la Sala; luego, el abogado de la parte civil y del tercero civil y al final, el abogado del acusado. Inicialmente este examen era indirecto (por intermedio del director de debates, que actuaba como una suerte de filtro de las preguntas, permitiendo algunas y denegando otras). En este escenario, es decir, hasta el año 2004, en la práctica concreta, durante el examen del fiscal y de los Jueces del Tribunal, los abogados asumían una actitud totalmente pasiva y, desde los claustros universitarios, no existió jamás una pedagogía que permitiera ilustrar sobre los parámetros para realizar objeciones, pero además existía un grave inconveniente sistemático: si el abogado efectuaba alguna objeción a alguna pregunta de alguno de los jueces, quien resolvía la eventual objeción era el propio Juez o Tribunal, con lo cual se resiente gravemente el principio acusatorio, pues, definitivamente en tales supuestos el Juzgador tiene la condición de Juez y parte.

Mediante el decreto legislativo 983 del 22 de julio del 2007 (hace apenas dos años y medio), recién se modifica el artículo 244 del viejo C. de PP, y se establece que el acusado -siempre como primer momento del juicio oral-, "...es examinado por el fiscal, por los abogados de la parte civil, del tercero civil, por su abogado y por el Director de Debates, en ese orden. Los demás miembros de la Sala, sólo podrán examinar al acusado si existiera la necesidad de una aclaración. En todos estos casos, el interrogatorio será directo por los abogados".

Como puede advertirse, si bien se instaura la posibilidad de que el abogado de la defensa interrogue después del Fiscal y de los otros abogados, se mantiene el examen por el director de debates como una fase normal del procedimiento sin que se especifique que sólo es para pedir aclaraciones.

Dentro de este contexto, se mantiene una concepción básicamente inquisitiva del examen del acusado. Por ello es necesario tener en cuenta que, "El nuevo interrogatorio, en tal sentido, supondrá una de las mayores dificultades a enfrentar, en el nuevo modelo, si partimos de considerar que, en nuestra cultura y práctica procesal vigente, durante los juicios ordinarios que solemos llevar, sólo hemos aprendido a interrogar, básicamente, por imitación y/o por intuición acompañada de lógica". En definitiva, esta herencia cultural debe tenerse presente al encarar los retos de la reforma procesal penal, sin olvidar que, "en los primeros tiempos la regla general era que el magistrado tenía el derecho ilimitado de interrogar, mientras que las partes no podían hacerlo".

\section{El examen del acusado en el nuevo Código Procesal Penal del 2004}

En el Perú, los inevitables movimientos de reforma han permitido finalmente la promulgación del nuevo Código del 2004. En relación al tema que nos ocupa, la regulación aún no satisface a nuestro juicio, las características del principio acusatorio. En concreto, la regulación referida al examen del acusado en el Juzgamiento, está plasmada en el artículo 371.3 y en el artículo 376 del citado cuerpo normativo. En el artículo 371.3 se establece básicamente su libertad de manifestarse sobre la acusación y su derecho de solicitar ser oído en cualquier estado el juicio con el fin de ampliar, aclarar o complementar sus afirmaciones o de declarar si anteriormente se hubiera abstenido. En el artículo 376 se indica que si el acusado se rehúsa a declarar, se leerán sus anteriores declaraciones prestadas ante el Fiscal. Y en el caso en que acepte ser interrogado se sujetará a las siguientes reglas: "a) El acusado aportará libre y oralmente relatos, aclaraciones y explicaciones sobre su caso; b) El interrogatorio se orientará a aclarar las circunstancias del caso y demás elementos necesarios para la medición de la pena y de la reparación civil; c) El interrogatorio está sujeto a que las preguntas que se formulen sean directas, claras, pertinentes y útiles; d) No son admisibles preguntas repetidas 
sobre aquello que el acusado ya hubiere declarado, salvo la evidente necesidad de una respuesta aclaratoria. Tampoco están permitidas preguntas capciosas, impertinentes y las que contengan respuestas sugeridas. En los incisos $3 y$ 4 de este artículo se indica finalmente que: "3. El Juez ejercerá puntualmente sus poderes de dirección y declarará, de oficio o a solicitud de parte, inadmisible las preguntas prohibidas; 4 . El último en intervenir será el abogado del acusado sometido a interrogatorio".

\section{Incoherencia de la regulación del nuevo Código Procesal Penal con el principio acusatorio en lo referido al examen del acusado}

Creemos que la descripción antes realizada nos permite constatar que, existen serios problemas de coherencia entre la forma cómo está establecido el examen del acusado y el principio acusatorio.

Nos explicamos. En principio, el nuevo código incluye el examen del acusado en el título IV, referido a "la actuación probatoria", específicamente, en el tema del "orden y modalidad del debate probatorio" (Artículo 375). Cabe preguntarse si esta ubicación caracteriza a la declaración del acusado como elemento de prueba. La respuesta a nuestro juicio es que, esa regulación, por lo menos complica e impide una cabal interpretación de la lógica de los exámenes de los acusados, pues, fomenta la confusión, entre lo que debe considerarse actuación probatoria versus un acto de defensa. No se ha evaluado que, el principio de presunción de inocencia previsto en el artículo II del Título Preliminar del nuevo Código, incluye la necesidad de que el Estado instaure una "suficiente actividad probatoria de cargo, obtenida y actuada con las debidas garantías procesales". En consecuencia, bajo el sistema acusatorio, debe abandonarse la mala práctica de procurar confesiones; y entender que, la declaración de un acusado, no es un acto de prueba, sino, es un acto de defensa, sobre todo si se reconoce que, en nuestro medio no es posible considerar al acusado, testigo de su propio caso, para cuyos efectos sería necesario tomarle juramento, como sucede en los Estados Unidos, en cuyo supuesto, si se descubre una mentira, el acusado habrá cometido un nuevo delito (perjurio o falso testimonio).

De otro lado, debemos tener en cuenta que, la contradicción y la igualdad de armas son esenciales. En ese sentido, como sostiene San Martín: "El principio de contradicción, (...), implica por esencia la dualidad de sujetos procesales en posturas opuestas y la situación primordialmente expectante del juez"; así mismo, "El principio de igualdad de armas es fundamental para la efectividad de la contradicción. Como tal requiere que se reconozca a las partes los mismo medios de ataque y de defensa, esto es, idénticas posibilidades y cargas de alegación, prueba e impugnación [la STEDH del 13.10.1996, recaída en el Asunto Ankerl vs. Suiza, señaló que este principio requiere que a cada parte se le ofrezca una oportunidad razonable de presentar su causa en condiciones que no le coloquen en una desventaja importante con respecto a su adversario. En similar sentido se pronuncia Víctor Burgos Mariños, cuando refiere: "En la lógica del proceso adversarial o de partes, la convicción judicial se forma del contradictorio realizado durante el juicio, mediante la introducción y contradicción de pruebas por las partes, y sobre la base de la mejor acreditación del relato afirmado por alguna de ellas. Ya no pesa sobre el juez, la obligación de la búsqueda de la verdad, sino que ahora, las partes buscan acreditar su relato, y dependerá de su habilidad en la presentación de su caso y en la ejecución de su estrategia probatoria, si logran convencer al juez quien tiene la versión más sólida y creíble, y si es así, así lo declarará el Juez en su sentencia."

Si bien para algunos autores, en el nuevo Código no existen posiciones de privilegio, sin embargo, consideramos que los resabios inquisitivos, por ende las incoherencias con el sistema acusatorio son más que evidentes, pues, no sólo se incluye el examen del acusado dentro del debate probatorio, sino además, el Código señala que esta actuación debe producirse en primer lugar (Artículo 375 inciso a) lo que podría resultar poco conveniente para la teoría del caso de la defensa; es más, es el Fiscal quien da inicio a los exámenes del acusado (Artículo 375 inciso 3), cuando se supone que quien debería iniciar el examen para intentar demostrar su teoría del caso, en el contexto del principio acusatorio, tendría que ser el abogado de la defensa, a propósito de los principios mencionados líneas arriba. Finalmente, se encarga al Juez (Artículo 376, 
inciso 3) la facultad de declarar de oficio o a solicitud de parte la inadmisibilidad de las preguntas prohibidas.

El conjunto de estas disposiciones cuestionables, ha generado que no exista una actuación uniforme ni mucho menos predecible, en los diferentes distritos judiciales en los que está vigente el nuevo Código. En alguno lugares como por ejemplo en Huaura, para compatibilizar la dinámica del examen del acusado con el principio acusatorio, los jueces, fiscales y abogados, se han puesto de acuerdo en que, quien debe interrogar en primer lugar al acusado, es su propio abogado, correspondiéndole el contra examen al fiscal; sin embargo, en otros distritos judiciales como Chiclayo por ejemplo, siguen la pauta del Código, es decir, examina en primer lugar el Fiscal y luego lo hace el abogado.

A estas incoherencias y tendencias disímiles, debemos agregar un fenómeno referido a la capacitación. En el contexto de las actividades de implementación, se ha contado con capacitadores de diferentes escenarios culturales que aportan diferentes técnicas de examen y contra examen, tanto de los acusados como de testigos y peritos. Los capacitadores norteamericanos y Portorriqueños, por ejemplo, son sumamente rígidos en exigir que el contra examen, aún tratándose de acusados, debe efectuarse exclusivamente con preguntas cerradas y sugestivas; en cambio los capacitadores chilenos, aunque refieren que lo recomendable y técnico es que el contra examen se efectúe con preguntas cerradas y sugestivas, no encuentran prohibido que puedan eventualmente efectuarse preguntas abiertas.

Sin embargo, con todo lo que se ha avanzado en Chile, uno de los países líderes en la región latinoamericana en el tema de la reforma, se han detectado también problemas en relación al tema que hemos abordado. Los profesores Andrés Baytelman y Mauricio Duce, han expresado por ejemplo que, "Un problema que se ha presentado en la práctica del funcionamiento de los juicios orales en nuestro país para proceder en la metodología de declaración por vía de examen directo y en el orden en que las partes decidan, se encuentra tratándose de la declaración del acusado que se regula en el inciso tercero del Articulo 326. Algunos tribunales de juicio han interpretado dicho inciso de una manera rígida... (...) nuestra interpretación del mismo es completamente diversa a las que hemos descrito. Para nosotros, dicho Artículo solo regula el caso específico en que el acusado decida prestar declaración una vez concluidos los alegatos de apertura. Si es que no desea hacerlo en ese momento, es evidente que podrá prestar declaración cuando la defensa así lo estime conveniente y siempre bajo el formato en el que declaran todos los testigos. Esta solución, junto con ser más consistente con los valores del sistema detrás de la regulación de la declaración del acusado en juicio, resulta coherente con la lógica de litigación que hemos venido examinando la cual intenta resguardar; por una parte, el derecho de las partes a presentar su caso de la forma en que sea más efectiva a los intereses que defienden...".

Compartimos la percepción de los reconocidos profesores, porque seguir el formato en el que declaran los testigos cuando se trata del examen de los acusados, es definitivamente más favorable al sentido teleológico del sistema acusatorio, no sólo por la necesidad de separar adecuadamente los roles, sino además, por la necesidad de garantizar todos los medios razonables posibles a la defensa para el cumplimiento de sus fines constitucionales. El reto en el caso peruano ( $y$, por lo visto, también en Chile y probablemente en el resto de la región), es lograr los consensos necesarios para que esta interpretación se produzca en forma homogénea y se genere la predictibilidad de los tribunales en el tema, lo que resulta un imperativo por el derecho constitucional a la igualdad y a la seguridad jurídica. Por ello cobra sentido lo mencionado por Pedro Angulo Arana cuando sostiene: "Lo más importante del nuevo modelo, en relación a nuestro tema, es que el interrogatorio resulta siendo considerado un ejercicio estratégico, tanto desde el punto de vista de la acusación como de la defensa, siendo, por ello, que debía haberse dejado el manejo del mismo a sus actores, esto es al fiscal y al abogado defensor. Lo lamentable es que, a partir del artículo 375 del NCPP, se aparece otorgando poderes y facultades al juez que, en realidad, corresponden a las partes".

De otro lado, creo necesario reconocer que una forma de propiciar esos consensos puede ser mediante propuestas de modificación legislativa, pero también, con la definición de pautas homogéneas de capacitación, lo que también podría canalizarse no sólo a través de actividades académicas, sino igualmente, mediante plenos jurisdiccionales y jurisprudencia vinculante. 


\section{REFERENCIAS BIBLIOGRAFCAS}

1. Angulo Arana P. El Interrogatorio de Testigos en el Nuevo Proceso Penal. la ed. Lima: Editorial Gaceta Jurídica; 2007.

2. Hendler ES. Derecho penal y Procesal Penal de los Estados Unidos. 1a ed. Buenos Aires: AD-HOC S.R.L.; 2006.

3. San Martín Castro C. Introducción al estudio del nuevo Código Procesal Penal en: El nuevo Proceso Penal. 1 a ed. Lima: Palestra Editores; 2005.

4. Burgos Mariños V. Principios Rectores del Nuevo Código Procesal Penal Peruano: El nuevo Proceso Penal. 1 a ed. Lima: Palestra Editores; 2005.

5. Baytelman A, Duce M. Litigación Penal, Juicio Oral y Prueba. la ed. Lima: Editorial Alternativas; 2005.

6. Angulo Arana P. El Interrogatorio de Testigos en el Nuevo Proceso Penal. 1 a ed. Lima: Editorial Gaceta Jurídica; 2007.

Correo electrónico:

iguerrerolopez@hotmail.com 